\title{
Influência da temperatura e do substrato na germinação de sementes de itaubarana (Acosmium nitens (Vog.) Yakovlev) - Leguminosae, Caesalpinoideae.
}

\author{
Vania P. VARELA ${ }^{1}$, Suely de Souza COSTA $^{2}$, Michele Braule P. RAMOS 3
}

\begin{abstract}
RESUMO
Acosmium nitens (Vog.) Yakovlev (Itaubarana), Leguminosae Caesalpinoideae, é uma espécie madeireira e ocorre em áreas inundáveis da Amazônia. O objetivo deste trabalho foi estudar a germinação de sementes de itaubarana sob diferentes condições de temperatura e substrato, utilizando-se como parâmetros a porcentagem e o tempo médio de germinação. Realizou-se um experimento, de acordo com o fatorial $4 \times 3$, nas temperaturas constantes de $20,25,30$ e $35^{\circ} \mathrm{C}$ e utilizando os substratos sobre areia (S.A), sobre papel (S.P) e sobre vermiculita (S.V). O delineamento estatístico empregado foi o inteiramente casualizado em esquema fatorial, com quatro repetições de 25 sementes por tratamento. Os resultados demonstraram que não ocorreu germinação das sementes quando semeadas sobre papel nas temperaturas de 30 e $35^{\circ} \mathrm{C}$. Para o substrato vermiculita, em todas as temperaturas testadas, foram observadas altas taxas de germinação das sementes com valores variando de 87 a $97 \%$. A temperatura de $30^{\circ} \mathrm{C}$ juntamente com o substrato vermiculita mostrou-se mais adequada para a germinação das sementes; nesta condição foi obtida a maior taxa de germinação (97\%) com tempo médio de aproximadamente 5,0 dias. Para o substrato sobre areia, as temperaturas de 20,25 e $30^{\circ} \mathrm{C}$ proporcionaram maiores porcentagens de germinação das sementes quando comparadas com a temperatura de $35^{\circ} \mathrm{C}$. Para as temperaturas de 30 e $35^{\circ} \mathrm{C}$, o substrato sobre vermiculita proporcionou maior taxa de germinação quando comparado aos demais substratos.
\end{abstract}

PALAVRAS-CHAVE

Acosmium nitens, temperatura, substrato, germinação.

\section{Influence of temperature and substrate on seeds germination of itaubarana (Acosmium nitens (Vog.) Yakovlev) - Leguminosae, Caesalpinoideae.}

\begin{abstract}
Acosmium nitens (Vog.) Yakovlev (Itaubarana), Leguminosae Caesalpinoideae, is an important timber species, which occurs in "varzea" (annualy flooded) Amazonian forests. This paper deals with germination rates of itaubarana, which were determined for seeds sown under different temperature and substrate conditions. The mean time lenght for germination was also included as measurement parameters. The experiment was carried out using a two-factor design with balanced data considering the effects of constant temperatures $\left(20,25,30 \mathrm{e} 35^{\circ} \mathrm{C}\right.$ ) and substrates (sand, paper and vermiculite) on the germination rates. Each level was replicated four times, and each replication contained twenty-five seeds. The results showed that seeds did not germinated when they were sown over paper at temperatures of 30 and $35^{\circ} \mathrm{C}$. High seed germination rates were observed on the substrate over vermiculite at all temperatures tested, with rates ranging from 87 to $97 \%$. The combination of temperature of $30^{\circ} \mathrm{C}$ and substrate over vermiculite showed to be adequate for seed germination; under this condition, the highest germination rate (97\%) was obtained with a mean time lengh of approximately 5,0 days. For substrate over sand, temperatures of 20,25 and $30^{\circ} \mathrm{Cprovided}$ the highest seed germination rates when compared with a temperature of $35^{\circ} \mathrm{C}$. For temperatures of 30 and $35^{\circ} \mathrm{C}$, the substrate over vermiculite provided the highest germination rate when compared with the other substrates.
\end{abstract}

\section{KEYWORDS}

Acosmium nitens, temperature, substrate, germination.

\footnotetext{
${ }^{1}$ Engenheira Florestal, M. Sc. Instituto Nacional de Pesquisas da Amazônia (INPA) - Cx. Postal, 478 - CEP 69083.000 - Manaus - AM. vaniav@inpa.gov.br

${ }^{2}$ Estatística, Doutora em Eng. de Produção-INPA. sscosta@inpa.gov.br

${ }^{3}$ Eng. Florestal, B. Sc. - INPA. mbraule@inpa.gov.br
} 


\section{INTRODUÇÃO}

A crescente exploração madeireira aliada ao desmatamento para fins agropecuários, na Amazônia vem causando o desaparecimento de muitas espécies que apresentam altos potenciais de utilização quer seja pelo valor ornamental, madeireiro, alimentício ou de preservação. A velocidade com que a floresta vem sendo destruída é razão suficiente para incrementar as pesquisas relacionadas com a propagação das espécies com o intuito de que sejam melhor utilizadas em programas de plantio.

As sementes constituem a via de propagação mais empregada na implantação de plantios. A busca de conhecimentos sobre as condições ótimas para os testes de germinação das sementes, principalmente dando ênfase aos efeitos da temperatura e do substrato desempenha papel fundamental dentro da pesquisa científica e fornece informações valiosas sobre a propagação das espécies.

A espécie em estudo, Acosmium nitens, vulgarmente conhecida como "itaubarana", pertencente à família Leguminosae - Caesalpinoideae, é uma árvore pequena que ocorre em lugares sujeitos a inundações temporárias e fornece madeira usada para dormentes, moirões, construção civil e naval (Silva et al., 1977). A. nitens ocorre no Brasil, nos estados doAmazonas, Pará, Roraima, Amapá e Mato Grosso (Silva et al., 1989; Marimon \& Lima, 2001), e em outros países da América Latina como Colômbia, Venezuela, Bolívia e Guiana (Yakovlev, 1969; Killeen \& Schulenberg, 1998).

A temperatura e o substrato para a germinação das sementes de Acosmium nitens são desconhecidos. Esse fato prejudica consideravelmente a avaliação da qualidade de lotes de sementes de Acosmium nitens cujos objetivos são a preservação e utilização dessa espécie com os mais variados interesses.

Os limites extremos de temperatura de germinação fornecem informações de interesse biológico e ecológico, onde sementes de diferentes espécies apresentam faixas distintas de temperatura para agerminação (Dau \& Labouriau, 1974 e Labouriau \& Pacheco, 1978). Dentro dessas faixas, pode ser considerada como temperatura ótima aquela na qual a mais alta porcentagem de germinaçãoé obtida, dentro do menor espaço de tempo. Seriam consideradas ainda a mínima e a máxima, respectivamente, como a mais baixa e a mais alta temperatura onde não ocorre germinação (Mayer \& Poljakoff-Mayber, 1989).

A temperatura ótima para a maioria das espécies vegetais está entre 20 a $30^{\circ} \mathrm{C}$ e a máxima entre 35 e $40^{\circ} \mathrm{C}$ (Marcos-Filho,1986). A faixa de 20 a $30^{\circ} \mathrm{C}$ também foi considerada por Borges \& Rena (1993) como a mais adequada para a germinação de um grande número de espécies florestais subtropicais e tropicais.

Para as sementes de urucum (Bixa orellana L.), as maiores percentagens de germinação foram obtidas sob temperatura alternada de $20-35^{\circ} \mathrm{C}$, em substrato rolo de papel (Gomes \& Bruno, 1992).

Cavallari et al. (1992) verificaram para sementes de Gmelina arborea Roxb que o melhor resultado de germinação foi alcançado na temperatura de $25^{\circ} \mathrm{C}$ em substrato vermiculita.

Andrade \& Pereira (1994) observaram que as temperaturas de 25 e $30^{\circ} \mathrm{C}$ juntamente com os substratos sobre papel e sobre vermiculita foram adequados para a germinação de sementes de Cedrela odorata $\mathrm{L}$.

O substrato utilizado nos testes de germinação apresenta grande influência no processo germinativo, uma vez que fatores como estrutura, aeração, capacidade de retenção de água, grau de infestação de patógenos, etc. podem variar de acordo com o tipo de material utilizado (Popinigis, 1977). A sua escolha deve ser feita levando-se em consideração o tamanho da semente, sua exigência com relação a quantidade de água, sua sensibilidade ou não à luz e a facilidade que oferece para realização das contagens e avaliação das plântulas (BRASIL, 1992).

Apesar do aumento considerável de conhecimentos relativos à análise de sementes de espécies florestais, gerado pelas pesquisas nestas duas últimas décadas, a maioria delas carece ainda de subsídios básicos referentes às exigências quanto as condições ótimas de germinação.

Face a inexistência de estudos enfocando as condições ótimas para germinação de sementes de Acosmium nitens, este trabalho teve como objetivo estudar os efeitos de diferentes temperaturas e substratos na germinação.

\section{MATERIAL E MÉTODOS}

Os frutos de itaubarana (Acosmium nitens (Vog.) Yakolev) dos quais foram extraídas as sementes utilizadas nesse estudo foram coletadas de árvores existentes na Estação Ecológica de Anavilhanas, cujo arquipélago está situado a pouco mais de 50 Km de Manaus, em 3/9/1999. Após a extração manual, as sementes foram tratadas para quebra da dormência, utilizandose ácido sulfúrico concentrado por 20 minutos.

Procurou-se estudar a influência de quatro temperaturas e três substratos na germinação de sementes de Acosmium nitens. As temperaturas constantes utilizadas foram $20,25,30$ e $35^{\circ} \mathrm{C}$, com variação de $+1^{\circ} \mathrm{C}$. Os substratos testados foram: sobre areia (S.A.), sobre papel (S.P.) e sobre vermiculita (S.V.).

Os testes de germinação foram conduzidos em câmaras, com fotoperíodo de 12 horas para todas as temperaturas, providas de lâmpadas fluorescentes de luz branca fria e fluxo luminoso de aproximadamente $10 \mu \mathrm{mol} . \mathrm{m}^{-2} \cdot \mathrm{s}^{-1}$ de radiação PAR (radiação fotossinteticamente ativa). As sementes foram colocadas para germinar em caixas plásticas transparentes (gerbox), nos substratos mencionados, com quatro repetições contendo 25 sementes por caixa.

As sementes germinadas foram contadas diariamente, quando apresentaram a emissão da raiz primária com comprimento maior ou igual a $2 \mathrm{~mm}$. Além da porcentagem de germinação, foi avaliado o tempo médio do processo germinativo.

Os tratamentos foram esquematizados em delineamento inteiramente casualizado, em esquema fatorial $4 \mathrm{X} 3$, sendo quatro temperaturas e três substratos. As porcentagens de germinação foram transformadas em arc sen $\sqrt{\mathrm{X} / \mathbf{1 0 0}}$, para normalização de sua distribuição (Bartlett, 1947), porém na tabela foram apresentadas as médias dos dados originais. Foi utilizado o teste de Tukey ao nível de 5\% de probabilidade, para comparação entre as médias quando houve significância no teste $\mathrm{F}$. 


\section{ACTA \\ AMAZONICA}

INFLUÊNCIA DA TEMPERATURA E DO SUBSTRATO NA GERMINAÇÃO DE SEMENTES DE ITAUBARANA (ACOSMIUM NITENS (VOG.) YAKOVLEV) - LEGUMINOSAE, CAESALPINOIDEAE.

\section{RESULTADOS E DISCUSSÃO}

As tabelas 1 e 2 mostram, respectivamente, as comparações entre as médias de porcentagem e do tempo médio de germinação para sementes de Acosmium nitens submetidas a diferentes temperaturas e substratos nos testes de germinação. No estudo da interação substrato e temperatura para os valores de porcentagem, observou-se que para o substrato sobre papel a temperatura de $25^{\circ} \mathrm{C}$ foi significativamente superior, quando comparada às temperaturas de $20,30 \mathrm{e} 35^{\circ} \mathrm{C}$. Em sementes de Cedrela odorata L., Andrade \& Pereira (1994), também observaram que a temperatura de $25^{\circ} \mathrm{C}$ e substrato sobre papel foi a melhor condição para a germinação.

Verifica-se que não ocorreu germinação no substrato papel quando foram utilizadas as temperaturas de 30 e $35^{\circ} \mathrm{C}$. Para o substrato sobre areia, as temperaturas de $20,25 \mathrm{e} 30^{\circ} \mathrm{C}$ mostraramse superiores estatisticamente a de $35^{\circ} \mathrm{C}$. Nas temperaturas de 20 , $25,30 \mathrm{e} 35^{\circ} \mathrm{C}$ não houve diferença significativa na porcentagem de germinação para o substrato sobre vermiculita (Tabela 1). Esses resultados indicam claramente que as sementes de $A$ nitens apresentamaltataxa de germinação numa amplafaixa de temperatura, diferente de outras espécies que tem uma faixa de temperatura ótima mais restrita (Cavallari et al., 1992; Andrade \& Pereira, 1994).

Os dados da Tabela 1 mostram que, na temperatura de $20^{\circ} \mathrm{C}$, não foi encontrada diferença significativa na porcentagem de germinação quando foram utilizados os substratos sobre areia e vermiculita, entretanto mostraram-se estatisticamente superiores ao substrato sobre papel. Na temperatura de $25^{\circ} \mathrm{C}$ as médias de germinação foram estatisticamente similares em todos os substratos testados. Em estudos com sementes de Sebastiana commersoniana (Baill.) Smith \& Downs, Santos \& Aguiar (2000) também constataram que não ocorreram diferenças na taxa de germinação, na temperatura de $25^{\circ} \mathrm{C}$, em função do substrato testado. Para as temperaturas de 30 e $35^{\circ} \mathrm{C}$, o substrato sobre vermiculita proporcionou maior taxa de germinação quando comparado aos demais.

Os dados apresentados na Tabela 2 permitem constatar que para o substrato sobre areia não ocorreu diferença no

Tabela 1 - Médias da porcentagem de germinação obtidas de acordo com as temperaturas e substratos testados em sementes de Acosmium nitens

\begin{tabular}{lcccc}
\hline \hline \multirow{2}{*}{ Substrato } & \multicolumn{4}{c}{ Temperatura $\left({ }^{\circ} \mathrm{C}\right)$} \\
\cline { 2 - 5 } & 20 & 25 & 30 & 35 \\
\hline S.A & A $90 \mathrm{a}$ & A 91 a & A 74 b & B 43 a \\
S.V & A 96 a & A 96 a & A 97 a & A 87 a \\
S.P & B 13 b & A 90 a & B 0 C & B 0 C \\
\hline
\end{tabular}

\section{$\mathrm{F}(1 \%)$}

Substrato (S) $168,07^{* *}$

Temperatura (T) 42,64**

Interação $(\mathrm{S} \times \mathrm{T}) \quad 18,02^{* *}$

C.V (\%) 16,02

Em cada coluna, médias seguidas da mesma letra minúscula e, em cada linha, médias precedidas da mesma letra maiúscula, não diferem significativamente entre si $(P>0,05)$. tempo médio de germinação entre as temperaturas de 25,30 e $35^{\circ} \mathrm{C}$. No entanto, observa-se um período maior para o processo germinativo na temperatura de $20^{\circ} \mathrm{C}$ quando comparada a de $25^{\circ} \mathrm{C}$. Para os substratos sobre vermiculita e papel, verifica-se também um tempo médio maior de germinação na temperatura de $20^{\circ} \mathrm{C} \mathrm{em}$ relação a de $25^{\circ} \mathrm{C}$.

Os dados de germinação e do tempo médio de sementes de Acosmium nitens em substrato de vermiculita, sob diferentes condições de temperatura, encontram-se na Figura 1. Para o substrato vermiculita, não foram observadas variações na porcentagem de germinação em função das temperaturas testadas, entretanto os dados de velocidade de germinação avaliados pelo tempo médio revelam que os melhores resultados foram alcançados com as temperaturas mais elevadas. Verificouse altas taxas de germinação das sementes em todas as temperaturas testadas em substrato vermiculita, entretanto com relação ao tempo médio, o menor valor foi obtido a $30^{\circ} \mathrm{C}$ indicando ser esta a temperatura ótima para o processo germinativo. Carvalho \& Nakagawa (1988) citaram que a temperatura ótima para porcentagem de germinação é diferente da ótima para velocidade de germinação, sendo mais elevada para esta última. Observa-se que na temperatura de $20^{\circ} \mathrm{C}$ foi necessário um tempo médio maior para o processo germinativo (8,8 dias) quando comparada com as demais temperaturas e que a exigência do tempo decresce com o aumento da temperatura. De acordo com Hendricks \& Taylorson (1976), baixas temperaturas podem reduzir as taxas metabólicas até que as vias essenciais ao início da germinação não possam mais operar.

Para as temperaturas de $30 \mathrm{e} 35^{\circ} \mathrm{C}$ foram observadas variações no tempo médio de germinação em função dos substratos, exceto quando foram utilizadas as temperaturas de 20 e $25^{\circ} \mathrm{C}$. Na temperatura de $30^{\circ} \mathrm{C}$, comparando-se o efeito do substrato, verifica-se um tempo médio menor de germinação (aproximadamente 5 dias) quando as sementes foram semeadas sobre vermiculita (Tabela 2). Esses resultados indicam ser esta condição mais favorável para a germinação das sementes de Acosmium nitens, pois além da alta taxa de germinação encontrada (97\%) a velocidade do processo germinativo ocorreu

Tabela 2 - Médias do tempo médio de germinação (dias) obtidas sob diferentes temperaturas e substratos testados em sementes de Acosmium nitens

\begin{tabular}{lcccc}
\hline \hline \multirow{2}{*}{ Substrato } & \multicolumn{4}{c}{ Temperatura $\left({ }^{\circ} \mathrm{C}\right)$} \\
\cline { 2 - 5 } & 20 & 25 & 30 & 35 \\
\hline S.A & A 8,0 a & B 6,5 a & AB 6,7 a & AB 7,3 a \\
S.V & A 8,8 a & BC 6,0 a & C 4,7 b & B 6,4 a \\
S.P & A 8,4 a & B 6,8 a & C 0 C & C 0 b \\
\hline F (1\%) & & & & \\
Substrato (S) & $6,07^{* *}$ & & & \\
Temperatura (T) & $8,71^{* *}$ & & & \\
Interação (S X T) & $2,32^{* *}$ & & & \\
\hline C.V (\%) & 13,86 & & & \\
\hline \hline
\end{tabular}

Em cada coluna, médias seguidas da mesma letra minúscula e, em cada linha, médias precedidas da mesma letra maiúscula, não diferem significativamente entre si $(P>0,05)$. 


\section{ACTA AMAZONICA}

INFLUÊNCIA DA TEMPERATURA E DO SUBSTRATO NA GERMINAÇÃO DE SEMENTES DE ITAUBARANA (ACOSMIUM NITENS (VOG.) YAKOVLEV) - LEGUMINOSAE, CAESALPINOIDEAE.

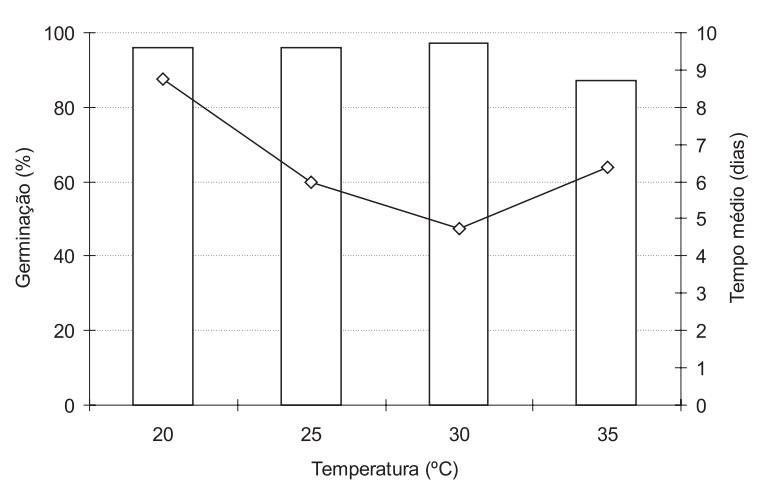

Figura 1 - Germinação de sementes de Acosmium nitens em substrato de vermiculita sob diferentes temperaturas.

com aproximadamente 5 dias. Na vermiculita, o contato entre as sementes e o substrato ébem maior, de acordo com Figliolia et al. (1993), sendo recomendado para as sementes de forma esférica com as de Acosmium. Para as sementes de Maquira sclerophylla a temperatura de $30^{\circ} \mathrm{C}$, em substrato vermiculita, foi indicada como ótima para a germinação (Miranda \& Ferraz, 1999).

A temperatura, juntamente com a umidade do substrato e a luz, são os principais fatores que influenciam a germinação de sementes (Mayer, 1986). A temperatura ideal de germinação, geralmente, varia dentro da faixa de temperaturas encontradas no local e na época ideal à emergência e estabelecimento das plântulas. A interação significativa entre temperatura e substrato foi mencionada por Figliolia et al. (1993), explicando que a capacidade de retenção de água e a quantidade de luz que o substrato oferece à semente podem proporcionar diferentes respostas obtidas até para a mesma temperatura, conforme ocorreu com as sementes de Acosmium nitens, neste ensaio.

Os substratos testados nesse estudo influenciaram sensivelmente a germinação das sementes de Acosmium nitens, conforme constatada pela análise dos resultados. É provável que além da capacidade de retenção dos substratos, as características intrínsecas que regulam o fluxo de água das sementes possam ter influenciado os resultados. A variação na disponibilidade de água dos substratos, fator comum nesse tipo de trabalho (Peterson \& Cooper, 1979), causa freqüentemente prejuízos à germinação das sementes, provocando diferenças entre as médias. Dos substratos testados, o papel de filtro mostrou-se desfavorável para a germinação das sementes de Acosmium nitens, confirmado pela análise dos dados onde verificou-se valores nulos de médias de germinação e de tempo médio nas temperaturas de 30 e $35^{\circ} \mathrm{C}$. Quando se utilizou o substrato papel de filtro em caixas gerbox, ocorreu uma desidratação rápida, excessiva e desigual, sendo necessário reumedecê-lo durante o decorrer do teste. A operação de reumedecimento do substrato após a semeadura, segundo BRASIL (1992) deve ser evitada uma vez que pode causar variações adicionais nos resultados. Verificou-se um grande desenvolvimento de fungos nesse substrato, o que contribuiu sensivelmente para a perda total de germinação das sementes.

\section{CONCLUSÕES}

Dos substratos testados, o papel de filtro mostrou-se prejudicial para a germinação das sementes de Acosmium nitens, onde verificou-se valores nulos de médias de germinação nas temperaturas de 30 e $35^{\circ} \mathrm{C}$.

Para o substrato sobre vermiculita, em todas as temperaturas testadas, foram observadas altas taxas de germinação das sementes de Acosmium nitens. Entretanto, a temperatura de $30^{\circ} \mathrm{C}$ juntamente com o substrato sobre vermiculita mostrouse mais adequada para a germinação das sementes desta espécie, pois além da alta taxa de germinação obtida (97\%) a velocidade do processo germinativo ocorreu com tempo médio de aproximadamente 5 dias.

Para o substrato sobre areia, as temperaturas de 20, 25 e $30^{\circ} \mathrm{C}$ proporcionaram maiores porcentagens de germinação das sementes de Acosmium nitens quando comparadas com a temperatura de $35^{\circ} \mathrm{C}$.

Para as temperaturas de 30 e $35^{\circ} \mathrm{C}$, o substrato sobre vermiculita proporcionou maior taxa de germinação quando comparado aos demais substratos.

\section{AGRADECIMENTOS}

As autoras agradecem ao técnico de laboratório Lúcio Flávio Pereira Batalha pelo auxílio na condução dos experimentos.

\section{BIBLIOGRAFIA CITADA}

Andrade, A.C.S.; Pereira, T.S. 1994. Efeito do substrato e da temperatura na germinação e no vigor de sementes de cedro - Cedrela odorata L. (Meliaceae). Revista Brasileira de Sementes, 16(1):34-40

Bartlett, M.S. 1947. The use of transformations. Biometria, 3:39-52

Borges, E.E.; Rena, A.B. 1993. Germinação de sementes. In: Aguiar, I.B. de; Pina-Rodrigues, F.C.M.; Figliolia, M.B. (Coord.). Sementes Florestais Tropicais. ABRATES. Brasília. p.137-174.

BRASIL. 1992. Regras para Análise de Sementes. Ministério da Agricultura e Reforma Agrária. SNDA/DNPV/CLAV. Brasília. 365pp.

Carvalho, N.M.; Nakagawa, J. 1988. Sementes-ciência, tecnologia e produção. Fundação Cargill. Campinas. 424pp.

Cavallari, D.A.N.; Wetzel, M.M.V. da S.; Batista, L.A.R. 1992. Substrato e temperatura na germinação de sementes de Gmelina arborea Roxb. Revista Brasileira de Sementes, 14(1):89-92

Dau, L.; Labouriau, L.G. 1974. Temperature control of seed germination in Perekia aculeata Mill. An. Acad. Bras. Cien. 46:311-322

Figliolia, M.B.; Oliveira, E.C; Piña-Rodrigues, F.C.M. 1993. Análise de Sementes. In: Aguiar, I. B. de; Piña-Rodrigues, F.C.M.; Figliolia, M.B. (Coord.). Sementes Florestais Tropicais. ABRATES. Brasília. p.37-74. 
Gomes, S.M. de S.; Bruno, R. de L. 1992. Influência da temperatura e substratos na germinação de sementes de urucum (Bixa orellana L.). Revista Brasileira de Sementes, $14(1): 47-50$

Hendricks, S.B.; Taylorson, R.B. 1976. Variation in the germination and amino acid leakage of seeds with temperature related to membrane phase change. Plant Physiology, 58(1):7-11

Killeen, T.J.; Schulenberg, T.S. 1998. A biological assessment of Parque Nacional Noel Kempff Mercado, Bolivia. Rapid Assessment Program Working Papers, 10:1-372

Labouriau, L.G.; Pacheco, A. 1978. On the frequency of isothermal germination in seeds of Dolichos biflorus L. Plant E Cell Physiol., 19:507-512

Marimon, B.S.; Lima, E.S. 2001. Caracterização fitofisionômica e levantamento florístico preliminar no pantanal dos rios Mortes-Araguaia, Cocalino, Mato-Grosso, Brasil. Acta bot. Bras., 15(2):213-229

Mayer, A.M. 1986. How do seeds sense their environment? some biochemical aspects of the sensing of water potencial, light and temperature. Israel Journal of Botany, 35:3-16

Mayer, A.M.; Poljakoff-Mayber, A. 1989. The germination of seed. Pergamon Press, Oxford. 270pp.

Marcos Filho, J. 1986. Germinação de sementes. In: Marcos Filho, J. (Ed.). Atualização em produção de sementes. Fundação Cargill. Campinas. p.11-39.
Miranda, P.R.M.; Ferraz, I.D.K. 1999. Efeito da temperatura na germinação de sementes e morfologia da plântula de Maquira sclerophylla (Ducke) C. C. Berg. Revista Brasileira de Botânica, 22(2):303-307

Peterson, J.R.; Cooper, P.G. 1979. Some considerations of water in the germination test. Seed Science Technology, 7:329-340

Popinigis, F. 1977. Fisiologia da semente. AGIPLAN. Brasília. 209pp.

Santos, S.R.G.; Aguiar, I.B. 2000. Germinação de sementes de branquinho (Sebastiana commersoniana (Baill.) Smith \& Downs) em função do substrato e do regime de temperatura. Revista Brasileira de Sementes, 22(1):120-126

Silva, M.F.; Lisbôa, P.L.B.; Lisbôa, R.C.L. 1977. Nomes vulgares de plantas amazônicas. CNPq/INPA. Manaus. 222pp.

Silva, M.F.; Carreira, L.M.M.; Tavares, A.S.; Ribeiro, I.C.; Jardim, M.A.G.; Lobo, M.G.A.; Oliveira, J. 1989. As leguminosas da Amazônia Brasileira - Lista prévia. Anais do XXXIX Congresso Nacional de Botânica, 2(1):193-234

Yakovlev, 1969. A review of Sweetia and Acosmium. Notes from Royal Botanic Garden, 29(3):347-355

\section{RECEBIDO EM 27/02/2002 ACEITO EM 19/01/2005}


